\title{
Critical Thinking Applied in Case Teaching of Professional Master
}

\section{Degree}

\author{
Ning yuxin ${ }^{1,} a^{*}$ \\ Lludan, b \\ ${ }^{1}$ Economics and Management school, Xi'an Shiyou University, Shanxi, Xi'an 710065 \\ ${ }^{2}$ Economics and Management school, Xi'an Shiyou University, Shanxi, Xi'an 710065 \\ anyx91@sina.com, b1193446374@qq.com
}

\begin{abstract}
In teaching case for professional master students, we could introduce the critical thinking. The paper firstly introduces the definition, characteristics of critical thinking and analyzes the correspondence to the case teaching, then the paper analyzes the processes and methods in case teaching. Finally, it shows the conclusion that the critical thinking could be helpful to improve the speculative capability and enforce the students' creative thinking.
\end{abstract}

Keywords: Professional Master Degree ; Case Teaching; Critical Thinking; Case Appraise

\section{Introduction}

Opinions on Implementing Postgraduate Education Innovation Program to Improve Creative Capability for Increased Training Quality, enacted by the Ministry of Education of China in 2005, requires nurturing postgraduates' creative awareness and improving their creative capability. And in Outline of China's National Plan for Medium and Long-term Education Reform and Development (2010-2020), the Ministry emphasized the continuity of that program. According to the program, the cultivation of critical thinking plays an important role and exerts an essential impact on cultivating graduate students' awareness of innovation and improving their innovation ability. During the process of professional degree graduate students being taught, case teaching integrates all points of knowledge across various domains in different stages through setting guidance, scenario simulation, scheme selection, action guiding and other modes so that students can truly feel how complicated the decision-making environment is in the real world. With the help of Internet search engines, however, these cases have not been finished satisfactorily when case teaching becomes popular. There are a considerable number of solutions having too much in common. These homogeneous solutions focus too much on "packaging" and "panoply", but forget and neglect the first and foremost aim of case creating and teaching[1,2,3]. Authors believe that it is the ignorance of a fundamental mindset training (the construction of critical thinking pattern) in professional degree graduate education stage that accounts for the current "dilemma" of case teaching. Teachers rightly overemphasize imparting knowledge and maintaining authoritativeness of knowledge. Instead, ignoring the guide of graduate students' thinking pattern. As we all know, postgraduate students can think, rethink, renew their knowledge and teach themselves well at this stage. Though there are numerous materials at hand, the lack of such guidance makes students stick to the stereotypes of worshiping authority, fearing to make mistakes and simply desiring to succeed. The result is therefore far from what case teaching aims for at first so that students will have much difficulty in developing creative thinking. Under the context, this paper probes into the construction of critical thinking in case teaching of professional degree, by which contributions can be made to case teaching and innovation[4,5,6]. 


\section{2 . Characteristics, Patterns and Competence Structure of Critical Thinking}

\subsection{Definitions and Characteristics of Critical Thinking}

\subsubsection{Definitions of Critical Thinking}

In 1910, John Dewey, American philosopher, put in How We Think, critical thinking reflects the subject's continuous and careful active thinking. Different scholars defined this notion differently. Dewey emphasized the reflexivity of critical thinking. That is to say, one must search new evidence for developing the proposition whether he goes for or against the opinion. Some scholars defined critical thinking through attitude and capability frameworks. Edward Glaeser stated that critical thinking represents a capability of systematically solving problems in a considerate attitude. Later in 1990, Peter Facione, after two years' effort using Delphi method, submitted a statement of expert consensus to Committee on Pre-College Instruction in Philosophy under American Philosophical Association, which specified that critical thinking comes along with purposeful self-regulated determination, interpretation, analysis and deduction. Karl Popper, another American philosopher in the mid and late 20th century, emphasized the importance of critical thinking in scientific creativity from philosophical perspective. Popper argued that, the essence of science is to propose criticism—-to overturn old theories and make new discoveries over and over again[7,8,9].

\subsubsection{Characteristics of Critical Thinking}

The above definitions reveal the following common characteristics of all critical thoughts:

(1) Skepticism and speculation: To thinking critically is to raise a set of questions about the presumption of a proposition or the proposition itself so that the proposition will be modified or abandoned. Questioning well-established beliefs and interpretations allows us to identify which ones have no evidence or rationality.

(2) Purpose and self-regulation: Critical thinking is by nature a tool for exploration. It is a ubiquitous thinking phenomenon, which features self regulation and correction.

(3) Openness, flexibility and fairness: A critical-minded person should have an open, fair and flexible mind. He or she should love rethinking and speculating to realize existing problems, tackle complicated problems neatly and search relevant information so as to establish appropriate evaluation standards. In this way, perfect solutions will come in their own right.

(4) Insight: Through skepticism and speculation, excellent critical-thinkers can develop useful insights endlessly to understand in depth the nature of existing problems so as to view the problems more reasonably.

\subsection{Capability Framework of Critical Thinking}

\subsubsection{Capability of Identifying, Determining, Argumenting, Interpreting and Deducting}

Capability framework of critical thinking incorporates elements like determination, argumentation and deduction; in turn, these elements form the argumentation framework of critical thinking. In the argumentation process, we should identify problems, define the nature of the problems, classify information, describe and pay attention to the information. Furthermore, we should turn problem into concept statement; establish relations between concepts and determinations, and explain the reason for a certain statement. Reason supported by arguments will become the prerequisite of further argumentation for in-depth deduction[10,11,12,13].

\subsubsection{Capability of Collecting Various Evidences, Analyzing and Processing Necessary} Information

To form a supportive prerequisite by collecting various evidences provides an effective guarantee for critical thinking. If one needs to support an opinion, he or she should perform information processing from the ill-ordered and complicated evidences. And then determine one point—which 
pieces of background information are available? If a clear-cut plan is required, one should clearly answer whether those pieces are usable; one should search available information and determine which pieces fall short. With this in mind, we will be clear for the further information collection and then go forward to the action schemes for information analysis and processing.

\subsubsection{Being Mature, Tolerant and Open Mind}

Critical thinking is not simply to deny something or to pick holes in someone else involved. Critical thinking has another vital dimension-keeping an open mind. That is to say, one should keep a fair and open mind, show concern for others' opinions and reasons, be willing to select alternate schemes in a tolerant and mature attitude.

\subsubsection{Capability of Communicating Cooperating and Transferring Information}

Based on interactive questioning and answering, critical thinking often is unbiased free discussion via communication, cooperation and information transfer.

\section{3 . Analysis of Correspondence between Critical Thinking and Case Teaching}

\subsection{Critical Thinking being Introduced based on Complicated, Changeable and Uncertain} Settings

Critical thinking emphasizes developing knowledge and capability from sheer practice and specific analysis, but opposes performing any empty, dull or abstract thinking or discussion. And complicated and various cases provide an excellent scene for exercising critical thinking. In brief, thinking in this manner can sharpen the capability of problem identification and analysis, evidence search and its quality verification, determination of evidence support, and other capabilities.

\subsection{Agreement between Openness of Case Analysis and Pattern of Critical Thinking}

Pattern of Critical Thinking is dissimilar to general logical argumentation, which often boasts a whole chain of determination, reasoning and argumentation. Many presumptions, on which case analysis depends, may give rise to different approaches of argumentation under critical thinking. Openness of case analysis agrees well with the approaches of critical thinking. This pattern emphasizes openness, and exercises creative thinking to identify and demonstrate problems and compare different solutions so that students can be trained in terms of self-teaching, understanding and developing.

\subsection{Case Teaching Inspiring Students to Think Critically}

As analyzed above, thinking critically involves individual capability and comprehensive quality. In case teaching, various case designs at different levels can help inspire students to grasp the basic skill, pattern and approach of critical thinking. For example, students should be enlightened as to how to identify information, exercise reasoning and stretch their minds for acquiring new knowledge.

\subsection{Case Teaching in Question Stimulating Students' Learning Interest}

By breaking the convention, universities can achieve interactive pedagogy via various approaches so that many solutions may arise from clashes of information exchange and thinking through team group, team competition, etc. In this way, class atmosphere will come alive immensely to let students study harder and get more involved.

\section{4 . Introduction and Application of Critical Thinking in Case Teaching}

\subsection{Case Introduction Stage:}

All cases and materials are introduced so that students will not overly depend on search engines anymore. The widespread use of these search engines makes either undergraduates or postgraduates 
rely too much on them. Students thus memorize nothing, think about nothing, do homework as a makeshift and even know nothing about where and why they go wrong. Over long time, they would be lazy to think, thus affecting their capability of information processing and the cultivation of critical thinking.

In the beginning of case introduction, natural real-world settings that are free of any expectation or preference should be presented to students as many as possible. University teachers should focus on the diversity of materials: Onsite interview, questionnaire, all kinds of news report, blog, WeChat and the like can be materials available.

\subsection{Themes Structure Based on Abundant Materials.}

What matters most in case introduction is finding problems. How to present discovered problems paves the way for finding solutions. When analyzing cases, students often cannot find any problems therein, tell major problems from minor ones, or even hierarchize all these problems. And describing problems unclearly or establishing priorities wrongly will directly affect the selection of subsequent argumentation structure and case schemes. So, it is necessary to help students establish proposition structure when all case materials are introduced fully. Proposition structure should be constructed according to hierarchy and priority of problems:

Level 1: About "What it is"? All such problems tell about the basics of case settings, persons and events.

Level 2: How to understand "What it is"? Statements on them simply express case settings, conflicts or obvious predicaments in abstract terms. Case solution often, on this level, lends itself to many explanations for different people who have various backgrounds in basic theory.

Level 3: Carve out solutions to level-2 problems by the basic principles.

Level 4: Think critically about level-3 solutions to decide whether it is necessary to return to level 2 for reconstructing problem priority.

Level 5: Propose comprehensive and more creative case solutions considering different argumentation routes.

Level 6: Perform final evaluation and selection to decide the feasibility and validity of schemes.

\subsection{Evidence being Collected, Information being Processed}

In case materials, which evidences can help clarify problems? Which evidences, if not available, may lead to uncertainties in both presumption and determination. Students should try to tap into the prerequisite and determination hidden in materials. In case teaching, the dissection of proposition roughly reflects the differences in the backgrounds of various students on all levels. Proposition dissection also falls into the following aspects:

(1) Why the problems in question occurred?

(2) What establishes the priority?

Dialectic thinking is the best way to arrive at complete perfection by improving thinking and argumentation through group critical discussion and deliberation. In the dissection of case propositions, different backgrounds and theoretical frameworks directly affect the judgment of learners. When designing and learning a case scheme, students should be taught how to argue for a proposition with critical thinking. Once such a proposition is proposed, they should search materials, evidences and theories for validating the assertion. So, it is natural to answer problems in a proposition. Good argumentation depends on its conformity with a given set of norms. And normative argumentation must satisfy the following conditions:

(1) Argumentation must have an authentic prerequisite;

(2) There is correlation between prerequisite and argumentation, which helps argumentation unfold itself; 
(3) There is correlation between argumentation and conclusion, which helps draw a convincing conclusion.

\subsection{Motivation of Students' Initiative and Emphasis on Procedural Learning}

Critical thinking beyond single argumentation contains something creative, and proposes and evaluates alternative views to select the best scheme. Critical thinking can inspire student initiative and emphasize procedural learning. This thinking pattern consists of evaluation, selection, application and determination of prerequisite and evidence. Only through such thinking exercise can students come to know that method is more important than knowledge. So, universities should teach students how to learn well, and solve problems through reasoning and thinking for increasing self-confidence, endurance, concentration, teamwork and growing sense of responsibility.

\section{Conclusion}

Critical thinking should pervade the whole process of case teaching. "To find out better answers, we should always be skeptical." This philosophy simply drives students to learn and explore more. Critical thinking pattern is also applied to the appraisal of case solutions. As professional master degree gets a higher place, case teaching is becoming the heart of postgraduate education. But in case teaching, we can still see how much students depend on standard answers, and they cannot or dare not challenge any given answer, thus sticking to the convention. Instead, critical thinking encourages students to boldly seek the best answer of any possible question. In this way, we will see explorative case solutions that produce different views along different routes. Indeed, only under the atmosphere of "letting all flowers bloom and all schools of thought contend" can case teaching be always creative.

\section{References:}

[1] Dong Yu Principles and Methods of Critical Thinking: Marching toward New Cognition and Practice [M]. Higher Education Press, 2010.

[2] Dong Yu Thoughts on Critical Thinking Based on Teaching in China's Science Students [J]. Collected in Symposium on the Construction of Curriculum with "Critical Thinking” , 2011, (5).

[3] Richard Paul , Linda Elder. Critical Thinking: Tools for Taking Charge of Your Professional and Personal Life [M]. Translated by Ding Wei Shanghai: Shanghai People’s Press, 2006: 17-19, 2006 : 17-19.

[4] Liu Li. The Influence of Undergraduates' Search Engine Dependency and its Interventions [J]. Social Sciences Journal of Universities in Shanxi, 2011, 23 (7): 109-111.

[5] David Hitchcock. Critical Thinking as an Educational Ideal [J], Journal of Higher Education, 2012, 33 (11): 54-63

[6] Gan Yongxin. Shaping Critical Thinking Courses with Critical Thinking[J]. Journal of Southwest University (Social Sciences Edition), 2010, 36 (6): 51-54.

[7] Brown Keeley . Asking the Right Questions: A Guide to Critical Thinking (7th Edition) [M]. Translated by Zhao Yufang and Xiang Jinhui . Beijing: China Light Industry Press, 20062006.

[8] FCT website. The Pressing Need for Critical Thinking [ EB/OL]. http://www. criticalthinking. org/ news/

3122009 press.dfm, 1985.

[9] Miao Siping The Influence of Critical Thinking Movement on General Education in the USA [J]. Tsinghua Journal of Education 2007, 28 (3): 99 -105.

[10] Wang Lu. A Critique of Critical Thinking [J]. Journal of Southwest University (Social Sciences Edition); 2009 (3): 64-69, 2009 (3): 64-69. 
[11]Wu, Bo, Haiying Shen, and Kang Chen. "Exploiting active sub-areas for multi-copy routing in VDTNs." Computer Communication and Networks (ICCCN), 2015 24th International Conference on. IEEE, 2015.

[12]Wu, Bo, Haiying Shen, and Kang Chen. "DIAL: A Distributed Adaptive-Learning Routing Method in VDTNs." Internet-of-Things Design and Implementation (IoTDI), 2016 IEEE First International Conference on. IEEE, 2016.

[13]Wu, Bo, and Haiying Shen. "A time-efficient connected densest subgraph discovery algorithm for big data." Networking, Architecture and Storage (NAS), 2015 IEEE International Conference on. IEEE, 2015. 